\title{
Article \\ Estimation Complete Combustion Coefficient in Rotary Kilns
}

\author{
Janusz Bujak ${ }^{1, *} \mathbb{C}$, Piotr Sitarz ${ }^{2}$, Krzysztof Bujak ${ }^{2}$, Sebastian Majkowski ${ }^{2}$ and Rafał Pasela ${ }^{1}$ \\ 1 Faculty of Environmental Engineering, Bydgoszcz University of Science and Technology, Kaliskiego 7, \\ 85-796 Bydgoszcz, Poland; rafal.pasela@pbs.edu.pl \\ 2 PPM PROMONT Bujak Sp. z o.o., Sp. K., Jagiellońska 35, 85-097 Bydgoszcz, Poland; \\ p.sitarz@promont.com (P.S.); k.bujak@promont.com (K.B.); s.majkowski@promont.com (S.M.) \\ * Correspondence: j.bujak@promont.com; Tel.: +48-501541185
}

check for

updates

Citation: Bujak, J.; Sitarz, P.; Bujak, K.; Majkowski, S.; Pasela, R. Estimation Complete Combustion Coefficient in Rotary Kilns. Energies 2022, 15, 1143. https://doi.org/10.3390/en15031143

Academic Editor: Ali Turan

Received: 21 January 2022

Accepted: 1 February 2022

Published: 3 February 2022

Publisher's Note: MDPI stays neutral with regard to jurisdictional claims in published maps and institutional affiliations.

Copyright: (c) 2022 by the authors. Licensee MDPI, Basel, Switzerland. This article is an open access article distributed under the terms and conditions of the Creative Commons Attribution (CC BY) license (https:// creativecommons.org/licenses/by/ $4.0 /)$.

\begin{abstract}
This paper presents a model-based analysis of variability of thermodynamic and chemical parameters in a rotary kiln (RK) during thermal treatment of animal waste. The core process of chemical treatment of waste takes place in RKs; the process involves heating, gasification and partial combustion of the waste. Control over these parameters, and especially the level of complete combustion, determines the quality and efficiency of the process. In operational practice, control and analysis of the variability of process parameters is complicated by the high degree of simultaneity of individual transformations, random disruptions of the process and metrological difficulties resulting from high temperature and chemical activity of the materials being processed. The purpose of preparing the model was to obtain a tool for predicting variability of selected process parameters. By definition, model calculations assume no influence of disturbances on output values, which makes it possible to acquire accurate results that can be compared with corresponding empirically obtained data. The result of the analyses conducted is a theoretical model of the analysed process and a graphical presentation of the calculation results in the form of graphs and charts. A formula for calculating the level of complete combustion and the results of calculation of this index on the basis of empirical data from an industrial waste incineration plant are also presented herein. The presented model is a useful tool providing an insight into interdependencies between selected process parameters and facilitating design of corrective actions oriented towards process optimisation.
\end{abstract}

Keywords: waste thermal treatment; rotary kiln; parameter predictions; process model

\section{Introduction}

Thermal treatment of animal waste is an activity that effectively eliminates the risks to human and animal health associated with this material. The advantages of this method are a relatively small amount of solid residue (ash) and the possibility to recover chemical energy of the waste. However, for the process of thermal waste treatment to be implemented properly, it must meet a number of conditions resulting from stringent legal regulations $[1,2]$, intended to maintain sanitary safety and reduce negative impact on natural environment. On the other hand, investors have their expectations regarding efficiency and low costs of this process. Furthermore, there are numerous technical and operational limitations related to the technology used and the design of thermal waste treatment installations (TWTIs). For these reasons, it is necessary to carry out research in order to improve and optimise this process taking into account the best available techniques (BATs) [3].

Of particular importance is the research and analysis of the main stages of thermal waste treatment, which are the thermodynamic and chemical processes carried out in the rotary kiln (RK) and the afterburning chamber $(\mathrm{ACH})$. The main process of chemical treatment of waste involving heating, gasification and partial combustion of the waste takes place in the combustion chamber. In the case of carbon and its compounds, they are converted to $\mathrm{CO}$ and $\mathrm{CO}_{2}$ in the chamber. The resulting ratio of these chemical compounds depends on a number of factors related to how the thermal treatment process 
is carried out. In the immediately downstream section of the installation, which is the afterburning chamber, the remaining carbon monoxide is afterburnt. Phenomena occurring in combustion and afterburning chambers can be described by parameters such as flue gas temperature, oxygen concentration in flue gas as well as mass and volume flow rate. Keeping these parameters within suitable ranges determines the quality and efficiency of the process. However, in operational practice, the control and analysis of the variability of process parameters is complicated by a high degree of simultaneity of individual transformations. Additionally, there are various random disturbances of the process and metrological (measurement) difficulties resulting from the prevailing high temperature and chemical activity of the processed materials. In this situation, it is advisable to first prepare a theoretical model of variability of the analysed parameters. The model allows prediction of correlations of selected input and output variables for a much wider range of changes of the analysed parameters than the range possible in the actual system. By definition, model calculations assume no influence of disturbances on output values, which makes it possible to obtain accurate results that can be compared with corresponding empirically obtained data. For this purpose, the universal detailed theoretical model described in paper [4], which is based on known balances of mass and energy fluxes allowing for the specificity of the thermal waste treatment installation, has been used.

A literature review indicates that presently a great number of studies are being conducted worldwide with the aim of improving the environmental safety as well as technical and economic efficiency of waste incineration processes. For example, issues related to reduction of emission of harmful substances to the natural environment are discussed in papers [5-10]. The conditions of energy and material recovery in these processes have been tackled in articles [11-13]. New ways of managing waste from the meat industry [14] and medical industry [15] have also been presented. In a number of papers, advanced mathematical modelling and numerical calculation techniques have been used to analyse complex, multivariate processes [16-20].

This paper presents a model-based analysis of RK operation relying on mass and energy balances. The results of the theoretical calculations have been visualised in the form of charts and graphs. The input and output parameters for the model have been identified descriptively. The input variables are mass fluxes of waste and air supplied to the RK combustion chamber with concurrent assumption of a level of complete combustion $\mathrm{CC}_{\mathrm{c}(\mathrm{rk})}$ (maintained ratio of $\mathrm{CO}_{2}$ to $\mathrm{CO}$ in the flue gas). The output variables analysed are flue gas temperature, flue gas mass flux and $\mathrm{O}_{2}$ concentration in the flue gas.

The general theoretical model used in this work allows the analysis of the combustion process of waste with different elemental composition and calorific value. For example, these can be materials with typical chemical and energy characteristics, such as medical waste, RDF (Refuse Derived Fuel), MBM (Meat Bone Meal). It is also possible to introduce any material by determining its elemental composition. The main parameters characterizing the burnt material are the percentage of carbon, hydrogen, oxygen and water. For the process analysis, it is also necessary to determine the non-flammable fraction (ash) in the combusted material. The share of other elements such as sulphur, chlorine, fluorine and nitrogen is also determined. The percentage of these elements is lower but as a result of thermal transformation processes, create chemical compounds dangerous to the environment. Appropriate neutralization methods must be designed and implemented for these compounds (sulphur dioxide, hydrogen chloride, hydrogen fluoride, nitrogen oxides).

In the presented study, it was decided to address the analysis for one type of waste (MBM with a defined elemental composition and energy value). The reason for this was the possibility of verifying the results on a facility that carries out the meal combustion process with high efficiency $(2.5 \mathrm{Mg} / \mathrm{h})$. This plant uses only locally produced, solid elemental waste meal. The flour is fed into the oven continuously, with a constant capacity by a screw conveyor. Thus, stable conditions are maintained with minimal influence of disturbing factors. Such conditions are difficult to maintain when other types of waste are incinerated. 
Typically, incinerators treat material (medical waste, animal waste) with a large random variation in elemental composition, moisture and ash content, and energy value.

The calculation formula presented in the paper is intended to estimate the degree of complete combustion in a rotary kiln for thermal transformation of MBM material. The calculations were based on empirical data recorded by the supervisory control system (a set of PLC controllers and visualization software) and by the exhaust gas monitoring system. The model presented in this paper has been used to analyse the variability of the level of complete combustion in RKs based on empirical data recorded in a large-scale meat bone meal (MBM) incineration plant.

\section{Assumptions for Model Calculations}

The thermodynamic and chemical processes (including gasification) associated with thermal waste treatment in RKs had been initially analysed using a theoretical model. A prediction of variability of the studied process parameters of the process under analysis was prepared using a theoretical model [4]. During configuration of the theoretical model, variables were selected in order for the model to best reflect the technology of the TWTI under study. A schematic diagram of the installation, showing the variables taken into account in the model tests, is presented in Figure 1; the input and output variables analysed in this case are also listed in that figure.

The algorithm included the following calculations for the output variables characterising the status of the waste incineration process immediately downstream of the RK as a function of the selected input variables with concurrent assumption of a level of complete combustion $C C_{c(r k)}$ :

$$
\begin{aligned}
& t_{o-f g(r k)}=f\left(\dot{m}_{i-w(r k)}, \dot{m}_{i-a(r k)}, C C_{c(r k)}\right) \\
& O_{2-f g(r k)}=f\left(\dot{m}_{i-w(r k)}, \dot{m}_{i-a(r k)}, C C_{c(r k)}\right) \\
& \dot{v}_{o-r f g(r k)}=f\left(\dot{m}_{i-w(r k)}, \dot{m}_{i-a(r k)}, C C_{c(r k)}\right)
\end{aligned}
$$

where $t_{o-f g(r k)}$ is flue gas temperature at RK outlet $\left({ }^{\circ} \mathrm{C}\right), \mathrm{O}_{2-f g(r k)}$ oxygen concentration in flue gas at RK outlet (\%), $\dot{v}_{o-r f g(r k)}$ unit real flue gas volume flux at RK outlet $\left(\mathrm{m}^{3} / \mathrm{kg}_{\mathrm{w}}\right)$, $\dot{m}_{i-w(r k)}$ MBM waste mass flux at RK inlet $(\mathrm{kg} / \mathrm{h}), \dot{m}_{i-a(r k)}$ mass flux of air supplied to RK $(\mathrm{kg} / \mathrm{h})$ and $C C_{c(r k)}$ assumed complete combustion coefficient (\%).

The complete combustion coefficient $C C_{c(r k)}$ is described by the following formula:

$$
C C_{c(r k)}=\frac{\dot{m}_{o-C O 2(r k)}}{\dot{m}_{o-C O}(r k)+\dot{m}_{o-C O 2(r k)}} \cdot 100
$$

where $\dot{m}_{o-C O 2(r k)}$ is $\mathrm{CO}_{2}$ mass flux at RK outlet $(\mathrm{kg} / \mathrm{h}), \dot{m}_{o-\mathrm{CO}(r k)} \mathrm{CO}$ mass flux at RK outlet $(\mathrm{kg} / \mathrm{h})$. It determines the status of the process of oxidation of the elemental carbon contained in waste in $\mathrm{RK}$, between the extreme possibilities where the reaction products are only $\mathrm{CO}$ or only $\mathrm{CO}_{2}$.

The waste mass flux $\dot{m}_{i-w(r k)}$ is controlled by controlling the screw conveyor through which the waste (MBM) in the plant under study is fed into the RK. The elemental composition, density and energy value of the burnt meal were determined through laboratory tests (Table 1). 


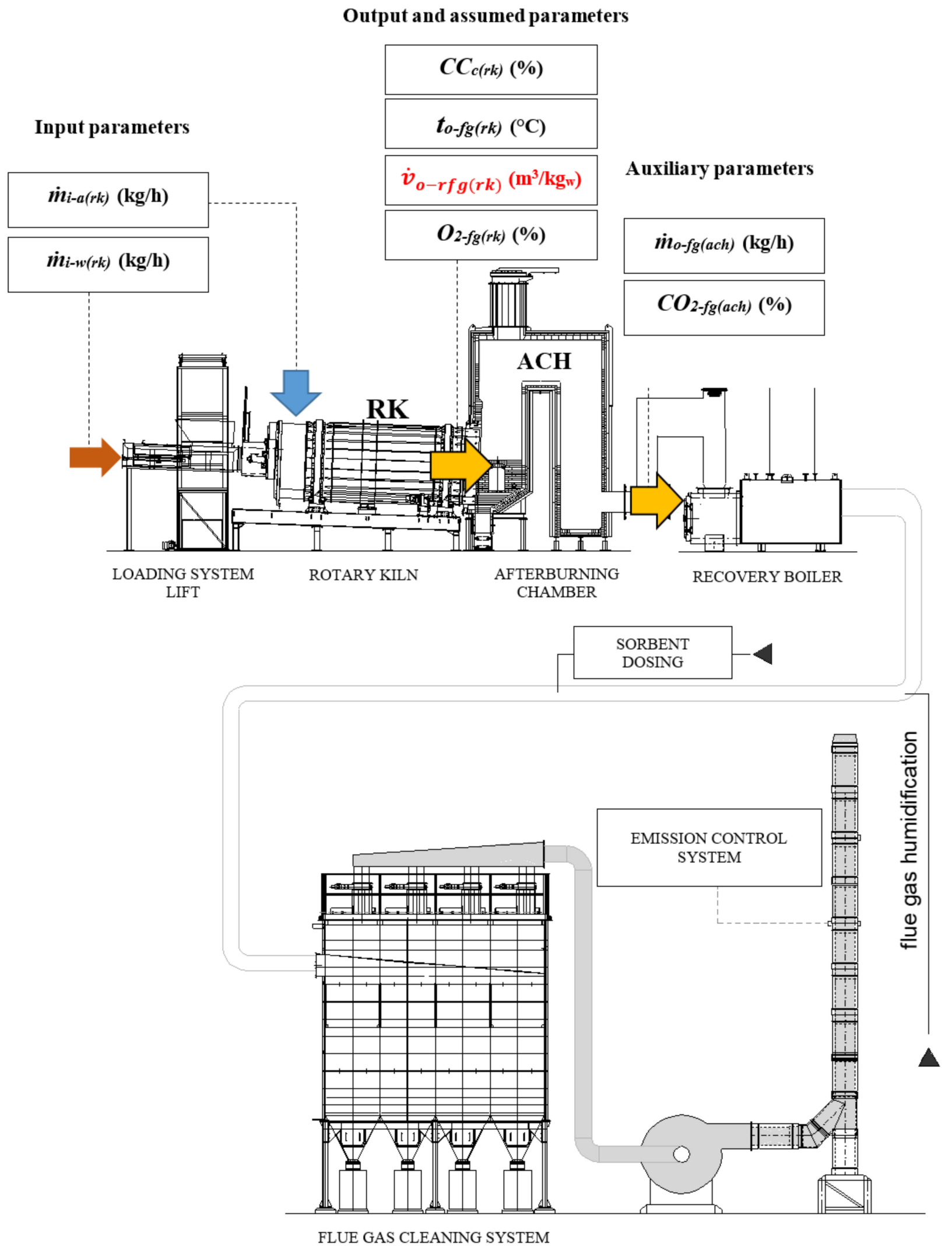

Figure 1. Input and output parameters of the computational model. 
Table 1. Chemical analysis of meat and bone meal processed in the tested facility.

\begin{tabular}{ccc}
\hline Parameter & Units & Measured Value \\
\hline Calorific value & MJ/kg & 15.8 \\
Ash & $\%$ & 25.6 \\
Water & $\%$ & 2.0 \\
Hydrogen & $\%$ & 7.4 \\
Sulphur & $\%$ & 0.5 \\
Chlorine & $\%$ & 0.4 \\
Carbon & $\%$ & 43.0 \\
Oxygen & $\%$ & 11.3 \\
Fluorine & $\%$ & 0.1 \\
Nitrogen & $\%$ & 9.7 \\
\hline
\end{tabular}

A second method of determining the mass flux of the incinerated waste $\dot{m}_{i-w(r k)}$ is also available; it involves calculations according to Formula (5) based on the mass flux of the flue gases discharged and the $\mathrm{CO}_{2}$ concentration as a percentage. In this case, it is necessary to assume that the flue gases are a product of complete combustion of waste having a constant elemental composition (the carbon content in waste is $43 \%$ ). In this paper, this method has been used to calculate the flux $\dot{m}_{i-w(r k)}$.

$$
\dot{m}_{i-w(r k)}=\dot{m}_{o-f g(a c h)} \cdot \frac{C O_{2-f g(a c h)}}{100} \cdot \frac{12}{44} \cdot \frac{100}{43}
$$

where $\dot{m}_{o-f g(a c h)}$ flue gas mass flux downstream of $\mathrm{ACH}(\mathrm{kg} / \mathrm{h}), \mathrm{CO}_{2-f g(a c h)} \mathrm{CO}_{2}$ concentration in flue gas downstream of $\mathrm{ACH}(\%)$.

The air mass flux $\dot{m}_{i-a(r k)}$ is controlled by controlling a set of supply fans and regulating throttles. The air is taken from the hall in which the TWTI is located. The fan control unit and the positions of the regulating throttles are controlled by a microprocessor-based controller according to the prepared algorithms maintaining the set parameters, such as excess of oxygen in the flue gases or temperature of the flue gases discharged from the RK.

In the analysis presented in this paper, a quotient $U A R_{r k}$ of air mass flux $\dot{m}_{i-a(r k)}$ and waste mass flux $\dot{m}_{i-w(r k)}$ has been introduced as a synthetic parameter simplifying description of the results obtained.

$$
U A R_{r k}=\frac{\dot{m}_{i-a(r k)}}{\dot{m}_{i-w(r k)}}
$$

where $U A R_{r k}$ is unit air consumption $\left(\mathrm{kg}_{\mathrm{a}} / \mathrm{kg}_{\mathrm{w}}\right)$.

In the calculations, the aforementioned universal model [4], which assumed different levels of $C C_{c(r k)}$ from $0 \%$ to $100 \%$ and temperatures of the produced flue gases $t_{o-f g(r k)}$ from 500 to $1400{ }^{\circ} \mathrm{C}$, was used. The model tests were also founded on the assumption that the raw material undergoing thermal treatment is MBM whose composition is specified in Table 1. Calculations were performed for all possible combinations of the variables under analysis. The research (calculation) plan prepared for this purpose is shown in Table 2. The calculations were performed using an algorithm written in VBA (Visual Basic for Applications).

Table 2. Model research plan.

\begin{tabular}{ccccccc}
\hline No. & Parameter & Symbol & Unit & Range & Step & Comments \\
\hline 1 & Complete combustion coefficient & $C C_{c(r k)}$ & $\%$ & $0 \div 100$ & 5 & variable \\
2 & Rotary kiln flue gas temperature & $t_{o-f g(r k)}$ & ${ }^{\circ} \mathrm{C}$ & $500 \div 14,000$ & 10 & variable \\
3 & Waste mass flux & $\dot{m}_{i-w(r k)}$ & $\mathrm{kg} / \mathrm{h}$ & $200 \div 800$ & 200 & variable \\
4 & Elemental composition of waste & - & - & Table 1 & - & constant \\
\hline
\end{tabular}




\section{Results of the Model Calculations}

\subsection{Visualisation of Results of the Model Calculations}

The theoretical distributions of parameters in the rotating combustion chamber of RK obtained by means of the computational model may be plotted in individual threedimensional graphs and summary charts. Figure 2 shows the variability of the flue gas temperature $t_{o-f g(r k)}$ (vertical z-axis) as a function of the unit air consumption $\left(U A R_{r k}\right)$ and the coefficient of complete combustion in the combustion chamber $\left(C C_{c(r k)}\right)$.

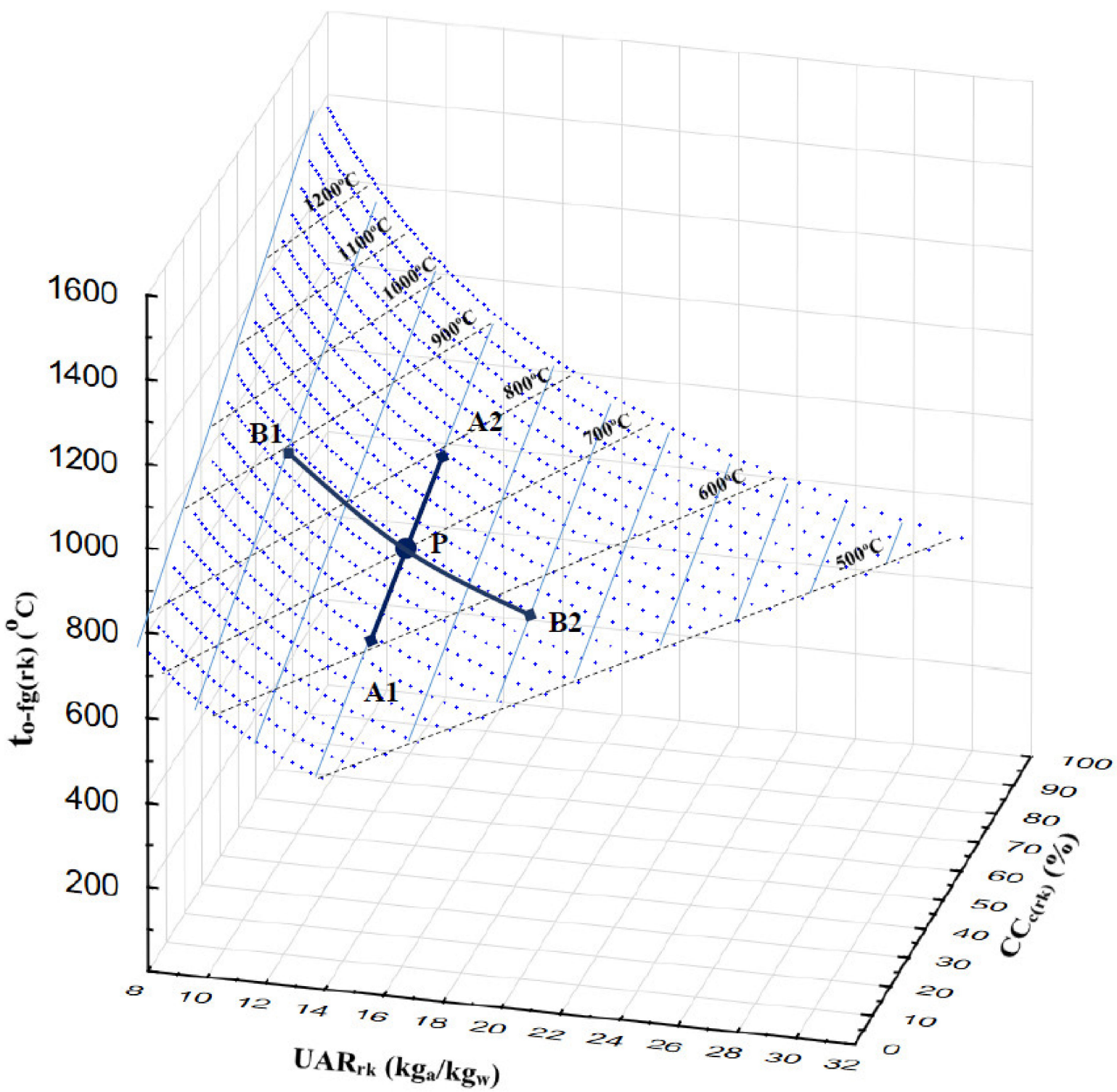

Figure 2. A temperature distribution chart for temperatures at RK flue gas outlet (rotary combustion chamber).

The chart shows an exemplary operating point $\mathrm{P}$ with parameters: $U A R_{r k}=14 \mathrm{~kg}_{\mathrm{a}} / \mathrm{kg}_{\mathrm{w}}$ and $C C_{c(r k)}=50 \%$. When $C C_{c(r k)}$ is increased, the flue gas temperature rises (point A2). Conversely, an increase of $\left(U A R_{r k}\right)$ causes a drop of the flue gas temperature (point B2).

Figure 3 shows a summary chart illustrating the correlation of several primary process parameters in RK with $U A R_{r k}$ (horizontal x-axis) and the coefficient of complete combustion in the combustion chamber $C C_{c(r k)}$ (vertical y-axis). The chart can be used to readily analyse the variability of the flue gas temperature $t_{o-f g(r k)}$, concentration of $O_{2-f g(r k)}$ in flue gas downstream of RK and real volumetric flow rate $\dot{v}_{r-f g(r k)}$ of the flue gas. The chart enables 
prediction of the strength and direction of the correlations between these output variables for the expected change in values of the input parameters.

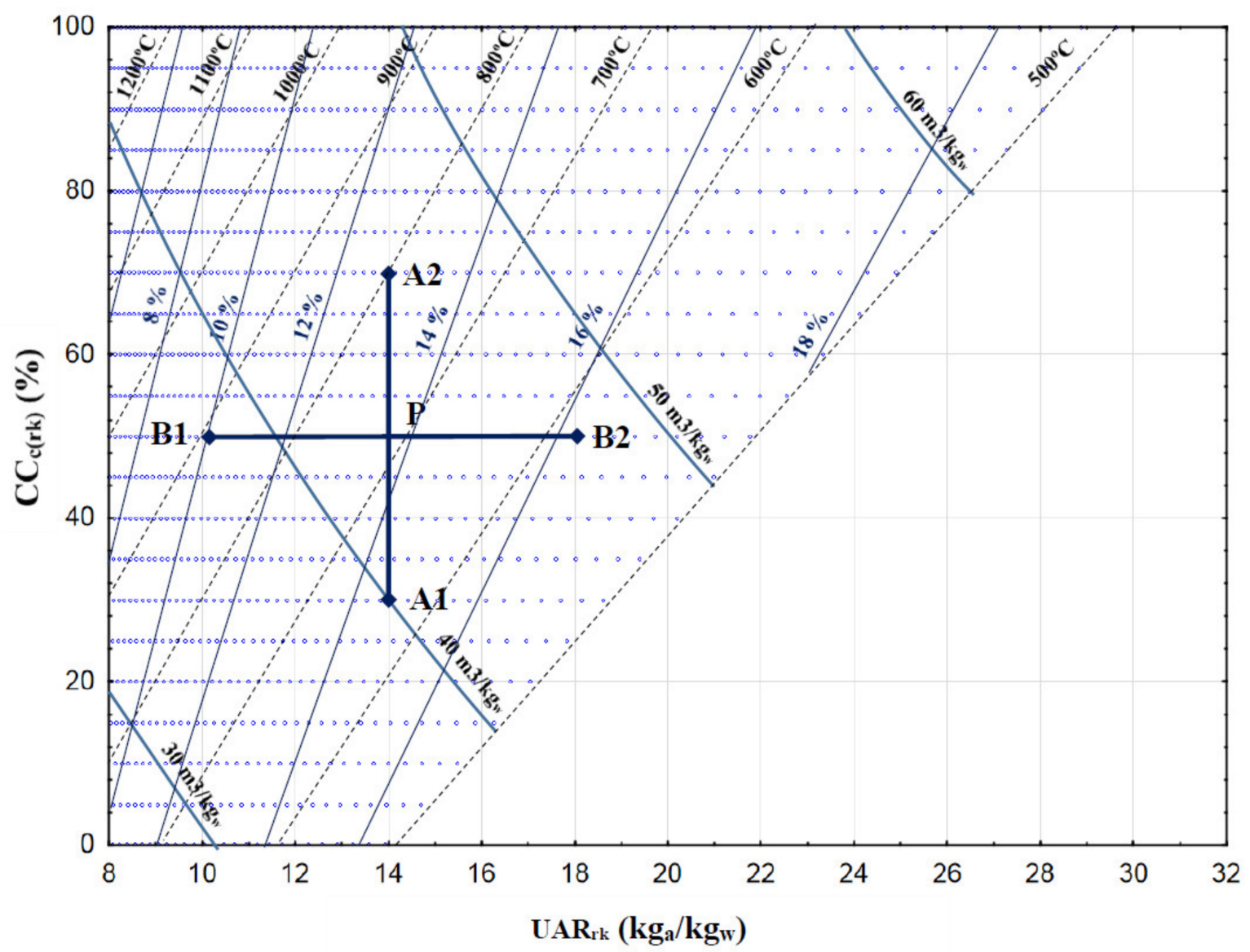

Figure 3. Chart of variability of process parameters in the rotary combustion chamber.

For instance, a transition from operating point $\mathrm{P}$ with coordinates: $U A R_{r k}=14 \mathrm{~kg}_{\mathrm{a}} / \mathrm{kg}_{\mathrm{w}}$ and $C C_{c(R K)}=50 \%$ to point $\mathrm{A} 2$ (increasing $C C_{c(r k)}$ to $70 \%$ ) causes a rise in flue gas temperature $\mathrm{t}_{\mathrm{o}-\mathrm{fg}(\mathrm{rk})}$ and unit real flue gas volume flux $\dot{v}_{r-f g(r k)}$, in parallel with a decrease in flue gas oxygen concentration $O_{2-f g(r k)}$. In another example, a transition from operating point $\mathrm{P}$ to B2 (increasing $U A R_{r k}$ to $18 \mathrm{~kg}_{\mathrm{a}} / \mathrm{kg}_{\mathrm{w}}$ ) entails a drop in flue gas temperature $t_{o-f g(r k)}$ and a higher flue gas oxygen content $O_{2-f g(r k)}$ and unit real flue gas volume flux $\dot{v}_{r-f g(r k)}$.

\subsection{Derivation of a Formula for $\mathrm{CC}_{c(r k)}$ Calculation}

A transformation of Equation (1) permits derivation of a formula for calculation of the otherwise directly immeasurable level of complete combustion $C C_{c(r k)}$.

$$
C C_{c(r k)}=f\left(t_{o-f g(r k)}, U A R_{(r k)}\right)
$$

Arguments of this function are temperature downstream of the rotary chamber $t_{o-f g(r k)}$ and unit air consumption $U A R_{r k}$ in RK as defined by Formula (6). In a regression analysis conducted for this purpose, response surface modelling was adopted for results achieved according to the plan in Table 2. where for each assumed combination of values $C C_{c(R K)}$ and $t_{o-f g(r k)}$ the value of $U A R_{r k}$ was calculated. The calculation of the parameters of the regression function was performed with the software STATISTICA. The following form of the function has been assumed:

$$
C C_{c(r k)}=a_{1}+a_{2} t_{o-f g(r k)}+a_{3} t_{o-f g(r k)}^{2}+a_{4} U A R_{r k}+a_{5} U A R_{r k}^{2}+a_{6} t_{o-f g(r k)} U A R_{r k}
$$


Formula (9) has been derived as a result. The notation omits the term in which coefficient $a_{3}$ was equal to zero.

$$
C C_{c(r k)}=-88.9-0.004 t_{o-f g(r k)}-2.015 U A R_{r k}-0.006 U A R_{r k}{ }^{2}-0.016 t_{o-f g(r k)} U A R_{r k}
$$

The coefficient of determination $\mathrm{R}^{2}$ for this model is 0.999 . The formula presented above is intended to estimate the degree of full combustion for waste with the composition given in Table 1. This formula allows for a quick, cyclical calculation of this parameter based on empirical data on the tested object. This enables, for example, the analysis of the correlation $C C_{c(R K)}$ with other parameters of the MBM waste incineration process. In order to analyze waste with a different elementary composition, a separate calculation should be made with an appropriately corrected plan. Table 2.

\section{Results of Calculations for Empirical Data}

The next stage of the analyses made practical use of Formula (9) to calculate the level of complete combustion $C C_{c(R K)}$ in an actual industrial facility equipped with a RK. In the plant in question, MBM goes through the process of thermal treatment. Elemental composition of the incinerated MBM, for which Formula (6) has been derived, is detailed in Table 1.

Hourly averages of the process parameters-temperature of flue gas downstream of the rotary chamber $t_{0-f g(r k)}$, mass flux of air supplied to the rotary chamber $\dot{m}_{i-a(r k)}$ and mass flux of the incinerated waste $\dot{m}_{i-w(r k)}$-recorded over a period of 5 days were used for the calculations. Temperature was measured using a TTSC-22 thermocouple sensor (measuring range $0 \div 1600{ }^{\circ} \mathrm{C}$, measurement error $2 \%$ ). The mass flux of the incinerated waste was calculated according to Formula (5) on the basis of flue gas parameters recorded downstream of the afterburning chamber by the flue gas monitoring system. A D-RX 250 monitor (measuring range $0 \div 50.000 \mathrm{~m}^{3} / \mathrm{h}$, measurement error $2 \%$ ) was used to measure the flue gas mass flux $\dot{m}_{0-f g(a c h)}$. Carbon dioxide concentration in flue gas $\mathrm{CO}_{2-f g(a c h)}$ was measured with a CX-4000 analyser (measuring range $0 \div 20 \%$, measurement error $2 \%$ ). The mass flux of air supplied to the combustion chamber $\dot{m}_{i-a(r k)}$ was determined based on specifications of the supply fan WPT700/28 and measurement of air pressure at the RK inlet manifold. The air pressure at the manifold was measured using a DPC4000 transducer (measuring range $0 \div 2500 \mathrm{~Pa} \%$, measurement error $0.5 \%$ ).

Results of calculations of $C C_{c(r k)}$ values (1-h average values), based on the empirical data recorder over 5 days, have been plotted on a chart in Figure 4 . In the timeframe under study, the calculated average value of the level of complete combustion $C C_{c(r k)}$ was $66.5 \%$. Dispersion of the measurements was $51.7 \%$ and the standard deviation was $8.79 \%$. UAR $R_{r k}$ values averaged $10.55 \mathrm{~kg}_{\mathrm{a}} / \mathrm{kg}_{\mathrm{w}}$ in the period under analysis. In addition, the studied parameter $C C_{c(r k)}$ and $U A R_{r k}$ were found to have been highly correlated. The correlation coefficient reached 0.87 . This means that in the course of thermal treatment of MBM waste in RKs increases of the complete combustion coefficient and increases of the unit air consumption for waste combustion occur in parallel. 


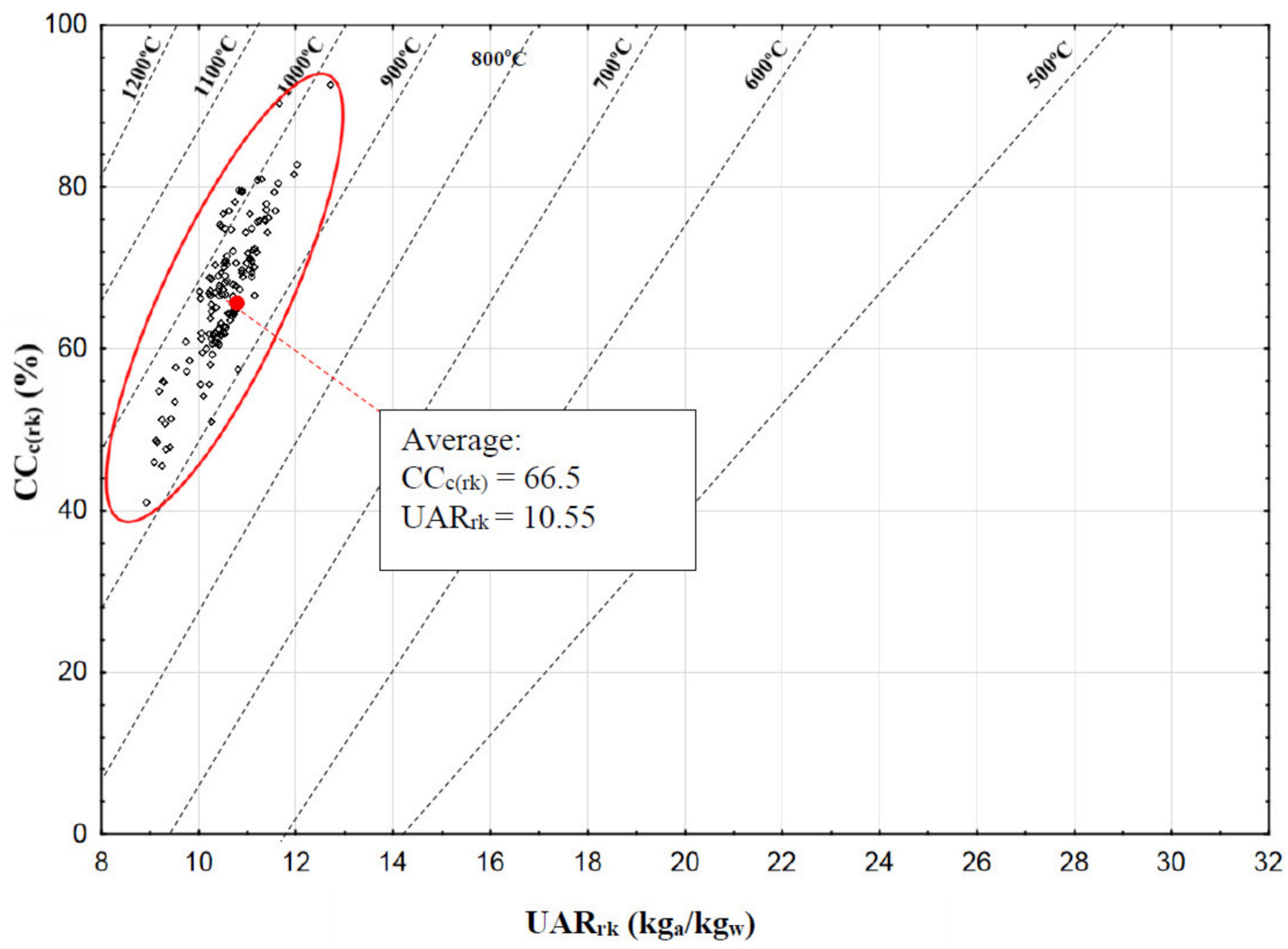

Figure 4. Chart of variability of process parameters in RK.

\section{Conclusions}

The theoretical model of the process of thermal waste treatment in RKs described in this paper permits a preliminary analysis of the process and prediction of the process parameters achieved. It is a useful tool providing an insight into interdependencies between selected process parameters and facilitating design of corrective actions oriented towards process optimisation. For example, it is possible to use the chart in Figure 3 to predict the direction and strength of concomitance of changes in flue gas temperature $t_{o-f g(r k)}$, concentration of $\mathrm{O}_{2-f g(r k)}$ in flue gas downstream of the rotary combustion chamber and unit real flue gas volume flux $\dot{v}_{r-f g(r k)}$ in case of a known increase in unit air consumption $U A R_{r k}$ or complete combustion coefficient $C C_{c(r k)}$. In operational practice, without the use of this tool, control and analysis of the variability of process parameters would be severely complicated by the high degree of simultaneity of individual transformations, influence of the process control system, random disruptions and measurement uncertainty.

The theoretical model may additionally be used for estimation of unknown values of $C C_{c(r k)}$ in the rotary combustion chamber. The calculations employing the empirical data recorded over a period of 5 days (with automatic correction algorithms turned off during this period) have attested to the determination that the average value of this parameter was $66.5 \%$, with an $8.79 \%$ standard deviation. Moreover, it has been determined that the variables $C C_{c(r k)}$ and $U A R_{r k}$ are strongly correlated (correlation coefficient $=0.87$ ), i.e., a decrease or increase of the complete combustion coefficient coincides with a respective decrease or increase of the unit consumption of air supplied for waste incineration.

The method of estimating the degree of complete combustion in a rotary kiln described in the article will be used by the authors for in-depth analysis and searching for optimization of waste incineration processes. Previously, the authors conducted a number of studies related to various technological, economic and ecological aspects of the incineration of medical, animal and plastic waste. In these cases, a significant difficulty for researchers is 
the random variability of the elemental composition and calorific value of waste. There were also many disturbing factors resulting from the implementation of these processes in industrial mode (e.g., variability in the amount of material processed or the level of waste energy collection). Contrary to that, in the installation analysed in this article, it is possible to conduct a program of tests related to $C C_{c(r k)}$ for one type of waste and with the minimization of disturbances. On the other hand, it is also planned to perform similar theoretical calculations and analyses for other types of waste.

Author Contributions: Conceptualisation, J.B., P.S., R.P., K.B. and S.M.; methodology, J.B., P.S., K.B. and S.M.; data curation, J.B., P.S., R.P., K.B. and S.M.; formal analysis, J.B., P.S., R.P., K.B. and S.M.; writing-review and editing, J.B., P.S., R.P., K.B. and S.M. All authors have read and agreed to the published version of the manuscript.

Funding: This research received no external funding.

Institutional Review Board Statement: Not applicable.

Informed Consent Statement: Not applicable.

Data Availability Statement: Data available on request due to restrictions, e.g., privacy.

Conflicts of Interest: The authors declare no conflict of interest.

\section{References}

1. The European Parliament and the Council of the European Union. Directive 2010/75/EU of the European Parliament and of the Council of 24 November 2010 on industrial emissions (integrated pollution prevention and control). Off. J. Eur. Union L 2010, 334, 17-119. Available online: https:/ / eur-lex.europa.eu/legal-content/EN/TXT/?uri=celex\%3A32010L0075 (accessed on 20 December 2021).

2. The Waste Incineration Directive 2000. The Waste Incineration Directive 2000/76/EC. Available online: https:/ / www.eea.europa. $\mathrm{eu} /$ themes/waste/links/waste-incineration-directive-2000-76-ec (accessed on 18 December 2021).

3. Commission Implementing Decision (EU) 2019/2010 of 12 November 2019 Establishing the Best Available Tech-Niques (BAT) Conclusions, under Directive 2010/75/EU of the European Parliament and of the Council, for Waste Incin-Eration (Notified under Document C(2019) 7987). Available online: https:/ / eur-lex.europa.eu/legal-content/EN/TXT/?uri=CELEX\%3A32019D2010 (accessed on 15 December 2021).

4. Bujak, J. Determination of the Optimal Area of Waste Incineration in a Rotary kiln Using a Simulation Model. Waste Manag. 2015, 42, 148-158. [CrossRef] [PubMed]

5. Johansson, J.; Normann, F.; Andersson, K. Techno-Economic Evaluation of Co-Removal of NOx and SOx Species from Flue Gases via Enhanced Oxidation of $\mathrm{NO}$ by ClO2 - Case Studies of Implementation at a Pulp and Paper Mill, Waste-to-Heat Plant and a Cruise Ship. Energies 2021, 14, 8512. [CrossRef]

6. Oh, H.; Annamalai, K.; Sweeten, J.M.; Heflin, K. Reburning of Animal Waste Based Biomass with Coals for NOx Reduction, Part II: Dairy Biomass (DB) and Coal-DB Blends. Energies 2021, 14, 8076. [CrossRef]

7. Bujak, J.; Sitarz, P. Reduction of NOx and CO Emissions through the Optimization of Incineration Parameters in a Rotary Kiln; Environment Protection Engineering. 2016. Available online: http:/ / epe.pwr.wroc.pl/2016/1-2016/Bujak_1-2016.pdf (accessed on 1 December 2021).

8. Bujak, J.; Nakielska, M.; Sitarz, P. Analysis of meat and bone meal clean combustion conditions. J. Clean. Prod. 2021, 280, 2. Available online: https:/ / www.sciencedirect.com/science/article/abs/pii/S0959652620344723 (accessed on 12 December 2021). [CrossRef]

9. Bujak, J.; Sitarz, P.; Pasela, R. Possibilities for Reducing CO and TOC Emissions in Thermal Waste Treatment Plants: A Case Study. Energies 2021, 14, 2901. [CrossRef]

10. Wielgosiński, G. Pollutant Formation in Combustion Processes, Advances in Chemical Engineering. Available online: https: //www.intechopen.com/books/advances-in-chemical-engineering/pollutants-formation-in-combustion-processes (accessed on 12 December 2021).

11. Bujak, J. Experimental Study of the Energy Efficiency of an Incinerator for Medical Waste. Appl. Energy 2009, 86, $2386-2393$. [CrossRef]

12. Bujak, J. Production of waste energy and heat in hospital facilities. Energy 2015, 91, 350-362. [CrossRef]

13. Giakoumakis, G.; Politi, D.; Sidiras, D. Medical Waste Treatment Technologies for Energy, Fuels, and Materials Production: A Review. Energies 2021, 14, 8065. [CrossRef]

14. Bujak, J. New insights into waste management-Meat industry. Renew. Energy 2015, 83, 1174-1186. Available online: https: / / www.sciencedirect.com/science/article/abs/pii/S0960148115300306 (accessed on 21 December 2021). [CrossRef]

15. Bujak, J. Thermal treatment of medical waste in a rotary kiln. J. Environ. Manag. 2015, 162, 139-147. [CrossRef] [PubMed] 
16. Bujak, J.; Nakielska, M.; Sitarz, P. Multidimensional Analysis of Meat and Bone Meal (MBM) Incineration Process. Energies 2020, 13, 5787. [CrossRef]

17. Sang, Z.; Bo, Z.; Lv, X.; Weng, Y. Numerical Investigations of the Influencing Factors on a Rotary Regenerator-Type Catalytic Combustion Reactor. Catalysts 2018, 8, 173. [CrossRef]

18. Giel, R.; Kierzkowski, A. A Fuzzy Multi-Criteria Model for Municipal Waste Treatment Systems Evaluation in-cluding Energy Recovery. Energies 2022, 15, 31. [CrossRef]

19. Becidan, M.; Ditaranto, M.; Carlsson, P.; Bakken, J.; Olsen, M.; Stuen, J. Oxyfuel Combustion of a Model MSW-An Experimental Study. Energies 2021, 14, 5297. [CrossRef]

20. Luo, Z.; Chen, W.; Wang, Y.; Cheng, Q.; Yuan, X.; Zhigang Li, Z.; Junjie Yang, J. Numerical Simulation of Combustion and Characteristics of Fly Ash and Slag in a "V-type" Waste Incinerator. Energies 2021, 14, 7518. [CrossRef] 